\section{Star-gazing funds should come down to Earth}

Sir - In January I reported ${ }^{1}$ on the results of an analysis I had undertaken on the cost-effectiveness of ground-based optical telescopes in the period 1978-94. I have now extended this analysis to include radiotelescopes and space-based observatories to see if a change is indicated in the balance of future investments in such astronomical observational facilities. As far as I am aware, this is the first such comprehensive cost-benefit analysis undertaken on either side of the Atlantic.

I have assessed the benefit or effectiveness of a particular facility by analysing the 15 per cent most cited papers published in Astrophysical Journal and Monthly Notices of the Royal Astronomical Society every half-year from 1958 to 1994 inclusive, at four-yearly intervals, and deducing which facilities were used to produce the new observations analysed in those papers. In many cases, more than one telescope or spacecraft were used to produce the data analysed in a given paper and, in that case, a scoring system was used $^{2}$ to take into account these different facilities, the total score for each paper being unity.

I have limited my analysis to observational facilities owned by governments and other institutions in the United States and British Commonwealth but, in the case of spacecraft, I have extended the analysis to include the European Space Agency, as that is where the United Kingdom spends most of its space-related funds.

My analysis of the total costs of these various facilities over the period 1956-92 shows that the balance of funding between capital and annual operational expenditure is very different for groundand space-based facilities, as shown in Table 1. On this basis, extra capital expenditure on ground-based observatories would be money well spent, if that could significantly reduce the annual operations costs. In the case of

\begin{tabular}{|c|c|c|}
\hline \multicolumn{3}{|c|}{ Table 1 Costs in 1992 US\$ (million) 1956-92 } \\
\hline Observatories & $\begin{array}{l}\text { Total annual } \\
\text { operations costs }\end{array}$ & $\begin{array}{l}\text { Written-off } \\
\text { capital costs }\end{array}$ \\
\hline $\begin{array}{l}\text { Ground-based } \\
\text { optical/IR }\end{array}$ & $3,300 \pm 500$ & $210 \pm 70$ \\
\hline $\begin{array}{l}\text { Ground-based } \\
\text { radio }\end{array}$ & $2,100 \pm 500$ & $580 \pm 60$ \\
\hline Space-based & $1,600 \pm 200$ & $4,600 \pm 500$ \\
\hline \multicolumn{3}{|c|}{$\begin{array}{l}\text { The period } 1956-72 \text { for the above costs is two years in } \\
\text { advance of the period for publication of papers. This is } \\
\text { to allow time for the observational data to be analysed } \\
\text { written up and published. }\end{array}$} \\
\hline
\end{tabular}

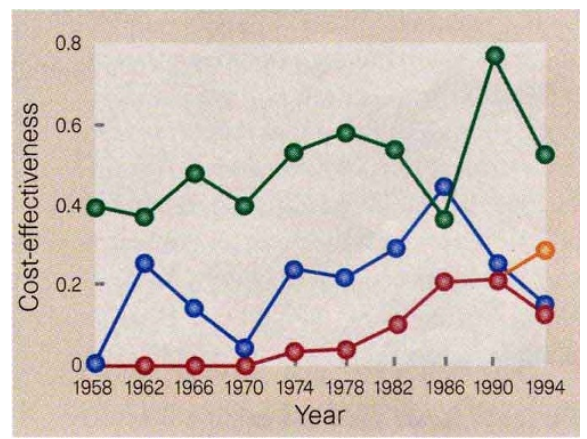

Figure 1 Plots of the cost-effectiveness as a function of time for ground-based optical/infrared and radio observatories and spacecraft, where the cost-effectiveness is defined as the number of highly cited papers per year divided by total annual costs in millions of 1992 dollars and where the total annual costs = annual operations costs + amortized capital costs. Optical is green, radio blue, spacecraft purple. The cost-effectiveness of spacecraft excluding the Hubble Space Telescope is shown in orange.

spacecraft, however, the situation is very different, and a major effort should be made to reduce the capital costs of such facilities. Alternatively, spacecraft should be designed for longer operational lifetimes, if this can be accomplished with only a small increase in capital costs.

Putting my analysis of costs and benefits together produces the cost-benefit results shown in Figure 1. This shows that there is a good case for increasing the investment in ground-based optical/infrared facilities at the expense of space-based astronomical observatories. Although the Hubble Space Telescope has been extremely successful, Figure 1 shows that it has not yet justified its high costs (both capital and operational), even though the relatively long planned lifetime (for spacecraft) of 15 years has reduced the annual write-off of capital costs. The US National Aeronautics and Space Administration's aim of producing a replacement facility in the next decade for about a quarter of the capital cost is the correct approach, provided the annual operations costs can be similarly reduced.

\section{David Leverington}

Physics Department,

Open University,

Walton Hall,

Milton Keynes MK7 6AA, UK

e-mail:D.Leverington@open.ac.uk

1. Leverington, D. Nature 385, 196 (1997)

2. Leverington, D. Q. J. R. Astr. Soc. 37, 643 (1996)
The one true faith

Sir - The Commentary article "Scientists are still keeping the faith" by Edward J. Larson and Larry Witham was superimposed on a large cross occupying more than half the height of the page (Nature 386, 435; 1997). Leuba's survey contained no reference to Christianity and could apply to Judaism or Islam, to name but two other possibilities. Contrary to the belief of many monotheists, there is not a monopoly on monotheism, and I assume that one does not have to sign an undertaking that one does not have a nonChristian background to be included in American Men and Women of Science. Mark R. Baker

Visual Sciences,

Radcliffe Infirmary,

Oxford OX2 6HE, UK

e-mail:mark.baker@green.ox.ac.uk

\section{No colour slides please}

Sir - Researchers used to spend days composing drawings to make slides for their dissertations, but most of the problems were overcome when computer programs arrived. Laser printers and plotters made all the drafts before impeccable graphs emerged. The only remaining thing to do was take a photograph. Speakers talked to a wideawake audience whose members could see each other and take notes.

But now everything has changed. New hardware offers the possibility of making slide pictures directly from the computer and, worse, of applying colour to blackand-white slides.

Presentations now start with a request for the lights to be switched off, and the speaker shows with satisfaction a slide where the conference title has been written in red, on a dark blue background, with a round corner frame in green and with the authors' names in bright yellow. People try to read the text from the abstract book and take notes without knowledge of Braille. Some participants will take advantage of the dark to enjoy a siesta. In a decade in which handicapped people have forced governments to remove physical barriers, colour-blind scientists are losing a battle with their own colleagues. I wonder whether such colourful slides are necessary and what their contribution, if any, is to scientific communication.

\section{Ricardo Borges}

Unidad de Farmacologia,

Facultad de Medicina,

Universidad de La Laguna,

Tenerife, Spain 